\title{
Correspondence
}

\section{Are CMHTs abandoning chronic cases?}

It would be helpful if Dr Singh (2000) would clarify his brief comments on what he refers to as the "backlog of chronic cases" and the primacy of throughput for community mental health teams. He seems to be arguing that community services have little to offer long-term patients and to support the diversion of resources away from them. It will be sad indeed if in the new millennium community services reimpose the second-class status, low expectations and unimaginative services for so-called chronic cases that characterised institutions in the last century. This was and is entirely inappropriate, in view of their illness courses and capacity for improved quality of life (Abrahamson, 1993); with appropriate approaches even the most long-term can stimulate community teams and improve morale (Abrahamson \& Fellow-Smith, 1991).

Abrahamson, D. (1993) Institutionalisation and the longterm course of schizophrenia. British Journal of Psychiatry, 162, 533-538.

-_ \& Fellow-Smith, E. (1991) A combined group and individual long-term out-patient clinic. Psychiatric Bulletin, 15, 486-487.

Singh, S.P. (2000) Running an effective community mental health team. Advances in Psychiatric Treatment, 6, 414-422.

Dr David Abrahamson Newham Community Mental Health Rehabilitation Team, 313 Shrewsbury Road, London E7 8QU

\section{Author's reply}

I thank Dr Abrahamson for pointing out that the comment about "backlog of chronic cases" could be misconstrued as suggesting that chronic illnesses deserve lower priority. My use of the term "chronic" was not meant to describe ill patients with ongoing and unmet need. Acute CMHTs do and should attempt to reduce disability, maximise function and improve quality of life of patients with chronica illness. However, faced with the relentless pressure of new referrals, team members may hold onto stable patients in remission as part of their caseload. This compromises the team's ability to take on new referrals and reduces effectiveness. It may also distract resources away from those with greater need. Dr Abrahamson's point that imaginative use of community services can improve outcome is well made. Having a community rehabilitation team is just such an imaginative use of resources.

Dr Swaran P. Singh Consultant Psychiatrist, Department of Psychiatry, University Hospital, Nottingham NG7 2UH.

Pseudoakathisia, akathisia and gender

Gervin \& Barnes (2000) presented an overview of drug-related movement disorders and a brief standardised examination for their assessment. We were interested to be reminded of the presentation of pseudoakathisia and the suggestion that the condition seems to be more common in males. Halstead et al (1994) reported this association, although the difference was not statistically significant. In a study of the prevalence of akathisia in 64 patients with mental disorder at St Andrew's Hospital, we found that all four patients with pseudoakathisia were male, but of the 14 patients with akathisia, nine were female (Stubbs et al, 2000). However, most epidemiological studies have not revealed any gender differences in vulnerability to akathisia itself.

A difference in susceptibility of the genders to developing akathisia and pseudoakathisia raises intriguing questions on the interrelationship between the two akathisia subgroups (Stubbs \& Halstead, 2000).

Gervin, M. \& Barnes, T. R. E. (2000) Assessment of drugrelated movement disorders in schizophrenia. Advances in Psychiatric Treatment, 6, 332-341.

Halstead, S. M., Barnes, T. R. E. \& Speller, J. C. (1994) Akathisia: prevalence and associated dysphoria in an inpatient population with chronic schizophrenia. British Journal of Psychiatry, 164, 177-183.

Stubbs, J. H. \& Halstead, S. M. (2000) Pseudoakathisia: a review and two case reports. Comprehensive Psychiatry, 41, $70-72$.

Stubbs, J. H., Hutchins, D. A. \& Mountjoy, C. Q. (2000) Relationship of akathisia to aggressive and self-referral centre. International Journal of Psychiatry in Clinical Practice (in press).

Jean Stubbs Head of Pharmacy, Christopher Mountjoy Consultant Psychiatrist, Department of Pharmacy, St Andrew's Hospital, Billing Road, Northampton NN1 5DG 